\title{
Fiebre Chikungunya
}
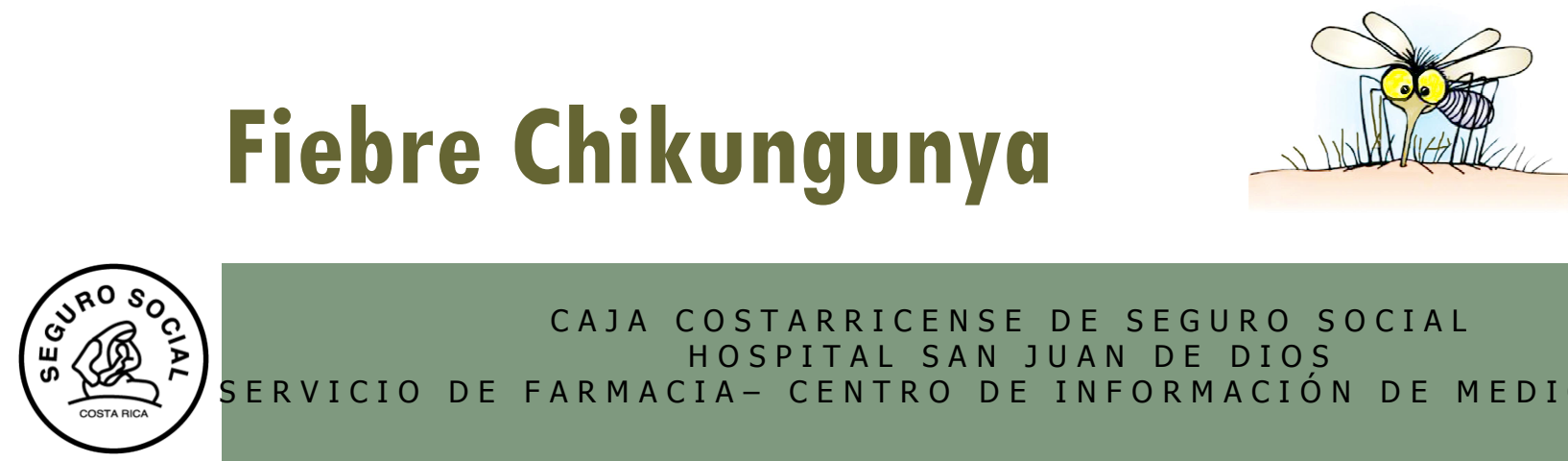

CAJA COSTARRICENSE DE SEGURO SOCIAL

HOSPITAL SAN JUAN DE DIOS

SERVICIO DE FARMACIA-CENTRO DE INFORMACIÓN DE MEDICAMENTOS

Volumen 4, número 4

Año 2014

\section{Introducción}

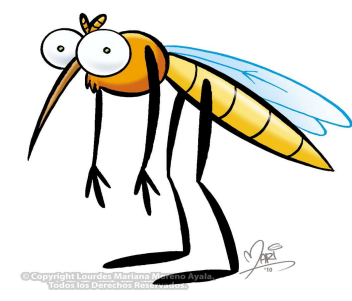

En la última década, principalmente después del 2005 la fiebre chikungunya ha reemergido en países de África, el sudeste asiático, la India y Oceanía, produciendo brotes importantes.

El virus se ha expandido a Europa principalmente por turistas que regresan a sus hogares con la infección.
En el 2007 se notificó por primera vez la transmisión de la enfermedad en Europa, en un brote localizado en el nordeste de Italia.

En diciembre del 2013 Francia notificó dos casos confirmados mediante pruebas de laboratorio en la parte francesa de la isla caribeña de St. Martin, desde entonces se ha confirmado que la enfermedad ha llegado a otras islas como Dominica, Guadalupe, Islas Vírgenes Británicas, Maritinica, Aruba y República Dominicana.

Cualquier país que tenga al vector de la enfer- medad, mosquitos del género Aedes spp, están en riesgo de presentar brotes.

En Costa Rica, solo se conocen casos importados, sin embargo, el Ministerio de Salud solicita estar alerta debido a que con la estación lluviosa los criaderos del mosquito se multiplican, lo cual hace a nuestro país en un área vulnerable para el desarrollo de la fiebre chikungunya.

Este boletín tiene como objetivo hacer una revisión de la transmisión, manifestaciones clínicas, tratamiento y situación actual de la enfermedad.

\section{¿Qué es la fiebre chikungunya?}

La fiebre chikungunya es una enfermedad vírica transmitida al ser humano por mosquitos del género Aedes spp.

Es común en áreas tropicales y subtropicales de África, la India, Oceanía y en el sudeste asiático (Figura \#1)

Se trata de un virus ARN del género alfavirus, familia Togaviridae.

Se describió por primera vez durante un brote ocurrido en sur de Tanzania en 1952.
El palabra chikungunya proviene del lenguaje Swahili (nombre de la tribu de Tanzania donde se descubrió el virus) "Kun qunwala" que quiere decir "el que se encorva o el que se dobla"
El palabra chikungunya proviene del lenguaje Swahili (nombre de la tribu de Tanzania donde se descubrió el virus) "Kun qunwala" que quiere decir "el que se encorva o el que se dobla"

Contenido:

$\begin{array}{ll}\begin{array}{l}\text { ¿QUÉ ES LA FIEBRE CHIKUN- } \\ \text { GUNYA? }\end{array} & \mathbf{1} \\ \begin{array}{l}\text { TRANSMISIÓN } \\ \text { MANIFESTACIONES CLÍNI- } \\ \text { CAS }\end{array} & \mathbf{2} \\ \begin{array}{l}\text { DIAGNÓSTICO DIFERNECIALL } \\ \text { DIAGNÓSTICO }\end{array} & \mathbf{4} \\ \begin{array}{l}\text { TRATAMIENTO FARMA- } \\ \text { COLÓGICO }\end{array} & \mathbf{6} \\ \begin{array}{l}\text { ALERTAS FARMACOVIGI- } \\ \text { LANCIA }\end{array} & \mathbf{8}\end{array}$




\section{Fiebre Chikungunya}

\section{Transmisión}

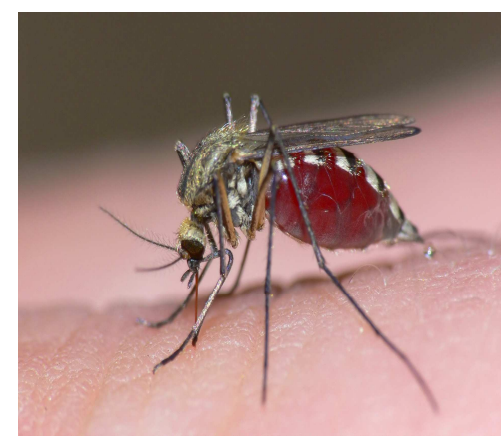

Figura \#2 Mosquito Aedes spp

\section{LOS MOSQUITOS}

IMPLICADOS EN LA TRANSMICIÓN SON AEDES AEGYPI $Y$ AEDES ALBOPICTUS DOS ESPECIES QUE TAMBIÉN PUEDEN TRANSMITIR OTROS VIRUS COMO EL DEL DENGUE

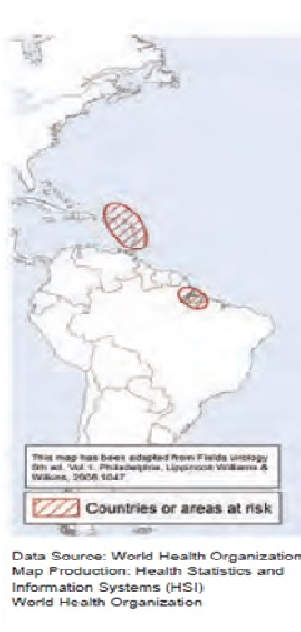

El virus se transmite de una persona a otra por la picadura de mosquitos hembra infectados.

Generalmente los mosquitos implicados son Aedes aegypi y Aedes albopictus dos especies que también pueden transmitir otros virus como el del Dengue. (Ver figura \#2)

Estos mosquitos suelen picar durante todo el periodo diurno, aunque su actividad puede ser máxima al principio de la mañana y al final de la tarde.

En África se ha encontrado que los primates no humanos y los mamíferos pequeños pueden ser reservorios de la enfermedad.

En regiones como Ugan- da se ha encontrado que mosquitos del género Mansonia spp, también pueden ser vectores de la enfermedad.

Los brotes de fiebre se han asociado a la estación lluviosa, que es cuando las poblaciones de mosquitos crecen.

Se ha observado que en África tanto el virus como el vector permanece principalmente en áreas selváticas y rurales, situación contrastante a la que presenta Asia, donde los brotes ocurren en zonas urbanas.

Los primeros brotes ocurrieron en 1954 en Filipinas y en los años 70 se reportaron otros brotes en Tailandia, Cambodia, Laos, Vietman, Pakistán y la India.
Entre 1982 y 1985 el virus llegó a Indonesia, Sumatra y las islas de Oceanía.

Los últimos brotes severos se había reportado en 1998 en Malasia, sin embargo, en la última década el virus ha resurgido.

Por ejemplo, en el 2005, se reportó un brote en la India, resultando en un total de 1300000 casos en 13 regiones diferentes.

Actualmente el virus se ha propagado a regiones como Europa, Australia y América desde regiones endémicas debido a que los viajeros regresan a sus hogares con alta viremia, convirtiéndose en fuentes de infección.

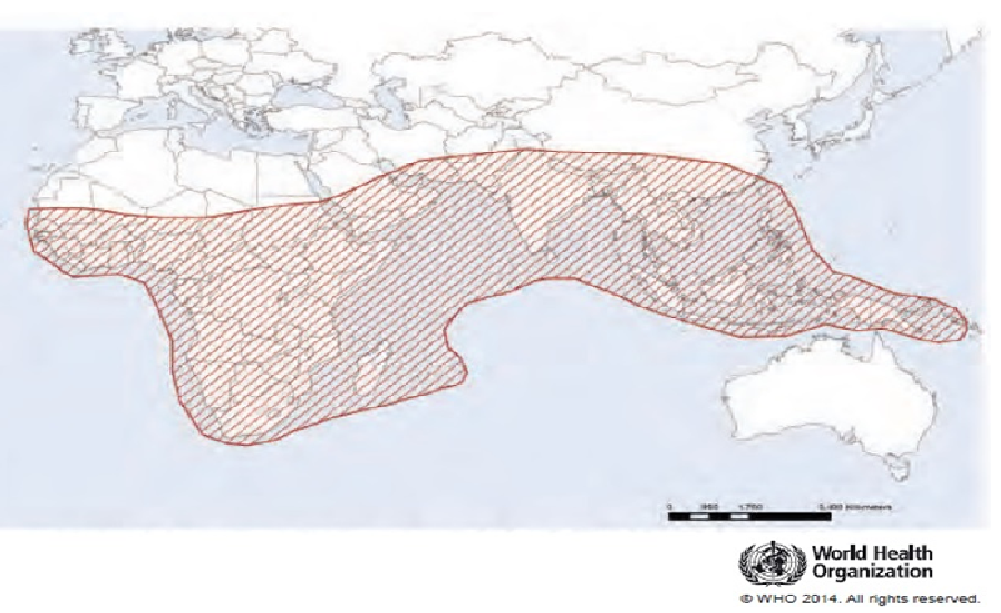

Figura \#1 Áreas en riesgo de Fiebre Chikungunya hasta agosto del 2014

Tomado de: http://www.who.int/ mediacentre/factsheets/ fs327/es/ Consultado el

2 de setiembre 2014 


\section{Volumen 4, número 4}

\section{Manifestaciones clínicas de la Fiebre Chikungunya}

La fiebre chikungunya afecta a todos los grupos de edad y a ambos géneros.

La infección tiene muchas similitudes a la provocada por el virus del Dengue (Ver sección "Diagnóstico diferencial")

Después de un periodo de incubación de 3 a 7 días (rango de 1 a 12 días) tras la picadura del mosquito, el virus causa una enfermedad febril generalmente asociada con artralgia/artritis y dolor de espalda.

También puede presentar dolor de cabeza, fotofobia y erupción cutánea en torso, cara y extremidades.
El dolor de las articulaciones tiende a ser peor en la mañana, aliviado por el ejercicio leve y agravado por los movimientos bruscos.

Los tobillos, las muñecas y las articulaciones pequeñas de la mano tiende a ser las más afectadas.

También puede afectar articulaciones más grandes como la rodilla, hombro y columna vertebral.

A pesar de que los síntomas resuelven espontáneamente en una a tres semanas, algunos pacientes puede permanecer con los síntomas reumatológicos (dolor articular) por años, puede ser tan severo que inclusive sientan la necesidad de permanecer encorvados. Esto es lo que se conoce como la fase crónica de la enfermedad, lo que conlleva a una disminución de la calidad de vida de los pacientes.

También se han descrito secuelas neurológicas como encefalopaía, Síndrome de Guillian Barré, parálisis flácida, entre otras, secuelas emocionales y dermatológicas.

La mortalidad es rara y ocurre principalmente en los adultos mayores.

En el cuadro \#1 se resumen las características clínicas de la fiebre chikungunya según la OMS

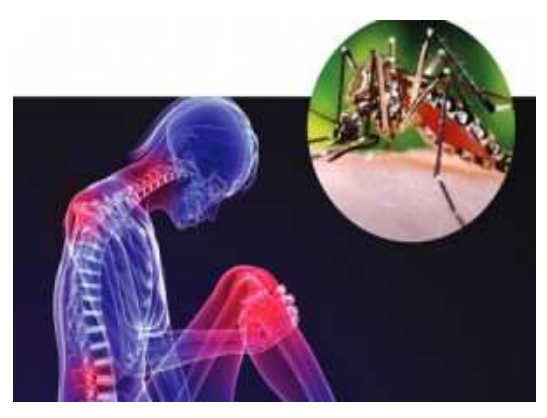

Después de un periodo de incubación de 3 a 7 días (rango de 1 a 12 días) tras la picadura del mosquito, el virus causa una enfermedad febril generalmente asociada con artralgia/artritis, dolor de espalda y cefalea.

\section{Cuadro \# 1 Características clínicas de la fiebre chikungunya}

\begin{tabular}{|l|ll|}
\hline \multicolumn{1}{|c|}{ Síntomas comunes } & \multicolumn{2}{c|}{ Otros síntomas posibles } \\
Fiebre & Estomatitis & Fotofobia \\
Artralgia & Úlceras orales & Dolor retroorbitario \\
Poliartritis & Hiperpigmentación & Vómito \\
Dolor de espalda & Mialgias & Diarrea \\
Cefalea & Dermatitis exfoliativa (niños) & Síndrome meníngeo \\
Erupciones cutáneas & & \\
\hline
\end{tabular}

Adaptado de Guidelines on clinical Managmente of Chikungunya fever, 2008, WHO 


\section{Fiebre Chikungunya}

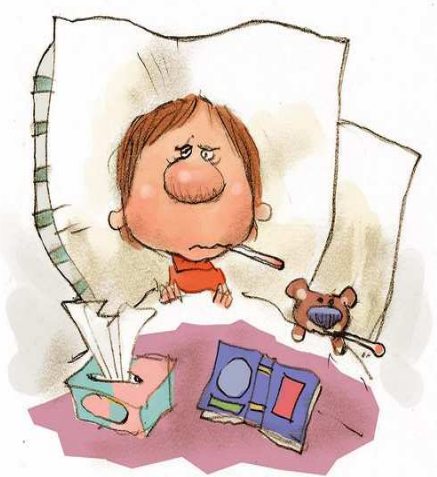

\section{Diagnóstico diferencial}

La fiebre chikungunya puede no tener las manifestaciones características 0 puede coexistir con otras enfermedades infecciosas o no-

El diagnóstico diferencial debe tener en cuenta las características epidemiológicas como lugar de residencia, historia de viajes y exposición.

Algunas de las enferme- dades que pueden considerarse en el diagnóstico diferencial son:

1. Dengue

2. Leptospirosis

3. Malaria

4. Meningitis

5. Artritis postinfecciosa

6. Rubeola

7. Sarampión
8. Parvovirus

9. Enterovirus

De todas las enfermedades anteriores, la que tiene mayor similitud es con el virus del dengue, en el cuadro \#2 se hace una comparación de los signos y síntomas de ambas enfermedades

\section{Cuadro \#2 Comparación de la fiebre chikungunya y el dengue}

- $\quad$ Frecuencia media de síntomas de estudios donde las dos enfermedades se compararon; $+++=70-100 \%$; $++=40-69 \%$; $+=10-39 \% ;+/-=<10-0 \%$

\begin{tabular}{|c|c|c|}
\hline Características clínicas & Fiebre chikungunya & Dengue \\
\hline Fiebre & +++ & ++ \\
\hline Mialgias & + & ++ \\
\hline Artralgia & +++ & $+/-$ \\
\hline Erupciones cutáneas & ++ & + \\
\hline Discrasias hemorrágicas & $+/-$ & ++ \\
\hline Shock & - & $+/-$ \\
\hline Leucopenia & ++ & +++ \\
\hline Linfopenia & +++ & ++ \\
\hline Neutropenia & + & +++ \\
\hline Trombocitopenia & + & +++ \\
\hline
\end{tabular}

Adaptado de OPS/OMS. Prepraración y respuesta frente a virus chikungunya en las Américas, 2010 


\section{Diagnóstico}

El diagnóstico de fiebre chikungunya se realiza sobre criterios clínicos, epidemiológicos y de laboratorio.

La confirmación por medio del laboratorio clínico es crucial para diferenciar de otras enfermedades de presentación clínica similar, pero con un abordaje terapéutico distinto.

Las pruebas de laboratorio que se describen a continuación se practican a nivel internacional por laboratorios oficiales.
1. Pruebas serológicas como el ELISA, pueden confirmar la presencia de anticuerpos IgM e IgG contra el virus chikungunya. Las mayores concentraciones de IgM se registran entre 3 y 5 semanas después de la aparición de la enfermedad y persisten unos 2 meses.

2. Cultivos víricos: durante los primeros 3 días de enfermedad. Los virus pueden aislarse mediante una muestra de sangre.

3. Reacción de cadena de la polimerasa con retrotranscriptasa, RTPCR: durante los primeros 3 días de enfermedad.

No existen datos hematológicos significativos. Normalmente se observa leucopenia con predominio de linfopenia. La trombocitopenia es rara. Se eleva generalmente la velocidad de sedimentación globular.

La proteína C reactiva aumenta durante la fase aguda y puede seguir estando elevada por algunas semanas

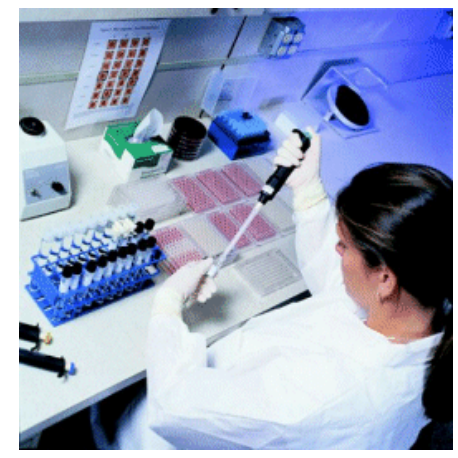

"El diagnóstico de fiebre chikungunya se realiza sobre criterios clínicos, epidemiológicos y de laboratorio"

\section{Situaciones especiales}

\section{Efecto sobre el embarazo}

La fiebre chikungunya parece tener una repercusión directa sobre el embarazo, con notificación de abortos espontáneos esporádicos y transmisión materno- infantil en el período perinatal.

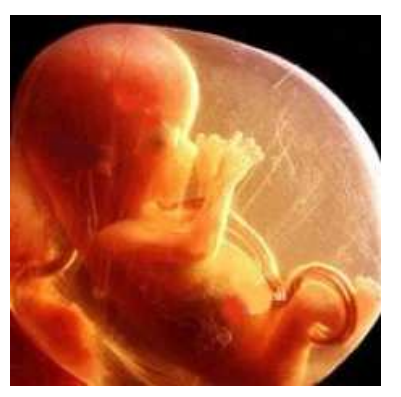

\section{Efectos sobre el recién nacido}

Las madres con fiebre chikungunya en el periodo perinatal ( -4 días a +1 días del parto) pueden transmitir la enfermedad a los recién nacidos mediante transmisión vertical.

Las manifestaciones en el neonato incluyen:

- Fiebre

- Dolor edema distal

- Manifestaciones en piel

- $\quad$ Crisis convulsivas

- Menigoencefalitis

- Anormalidades ecocardiográficas 


\section{Fiebre Chikungunya}
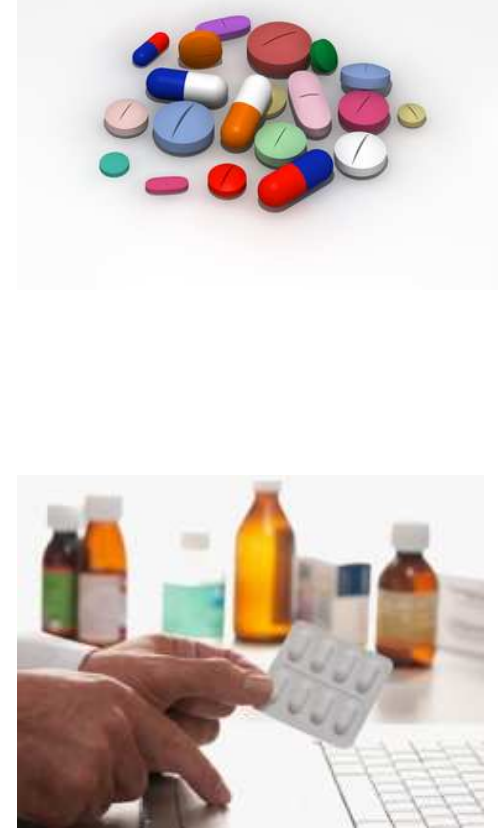

\section{Tratamiento farmacológico}

No existe ningún antiviral específico para tratar la fiebre chikungunya.

El tratamiento consiste principalmente en aliviar los síntomas, entre ellos el dolor articular, con antipiréticos, analgésicos óptimos y líquidos.

El acetaminofén es el medicamento de elección, inclusive puede ser útil en casos de Dengue mientras se espera la confirmación diagnóstica.

No hay comercializada ninguna vacuna contra el virus chikungunya.

Debido a que se trata de una enfermedad reemergente se están comenzando a utilizar en otros países medicamentos como la ribavirina y la cloroquina para la fase crónica de la enfermedad.

Se ha demostrado que la ribavirina tiene actividad moderada frente a virus ARN. Propiamente en el caso del virus chikungunya se ha observado que favorece el alivio de la artralgia en al fase crónica. Es importante destacar que el uso de ribavirina aún no es oficial y solo ha sido probado en pequeñas cohor- tes de pacientes, por lo que se requieren estudios adicionales que proporcionen mayor evidencia.

Por otra parte, también se ha estudiado el potencial terapéutico de la cloroquina al demostrar actividad antiinflamatoria en cultivos celulares infectados con virus chikungunya, al inhibir receptores proinflamatorios. Sin embargo, los pocos estudios realizados en pacientes con infección en fase crónica demuestran que el efecto beneficioso no es constante.

\section{Criterios diagnósticos Fiebre Chikungunya}

Criterio clínico

Fiebre $>38,5 \circ \mathrm{C}$ y artralgia severa o artritis
- Caso posible, cuando no es explicado por otras condiciones médicas como dengue, infección por alfavirus, artrisis o malaria
Criterio epidemiológico

Habita un área endémica o ha visitado un área endémica en los últimos 15 días antes del inicio de los síntomas
- Caso probable, si cumple con criterios clínicos y epidemiológicos, otros patógenos con características clínicas similares pueden habitar estas mismas áreas endémicas
Criterios de Laboratorio Aislamiento del virus, presencia de IgM- IgG
- Caso confirmado, si un paciente tiene pruebas de laboratorio positivas frente al virus chikungunya.

- Puede estar diagnosticado inclusive sin presentar síntomas 


\section{Medidas de salud pública}

Los pacientes infectados con el virus chikungunya son el reservorio de la enfermedad para otros en el hogar y en la comunidad, por lo tanto las medidas de salud pública para reducir al mínimo la exposición a mosquitos se convierten en imperativos para prevenir la diseminación del brote.

Se debe educar a la población acerca del riesgo de transmisión y las maneras de reducir al mínimo este riesgo al contro- lar la población de vectores.

Además se debe hacer énfasis que las medidas de prevención son las mismas que las empleadas para combatir la transmisión del virus del Dengue.

Eliminar el agua estancada en la basura, canoas o desechos alrededor del hogar y en zonas cercanas.

Reducir al mínimo el contacto vector- paciente.
Emplear malla en puertas y ventanas.

Utilizar repelentes.

De preferencia el paciente debe utilizar mandas largas y pantalones largos para cubrir sus extremidades.

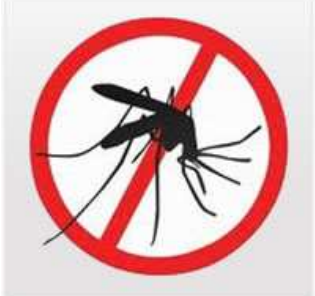

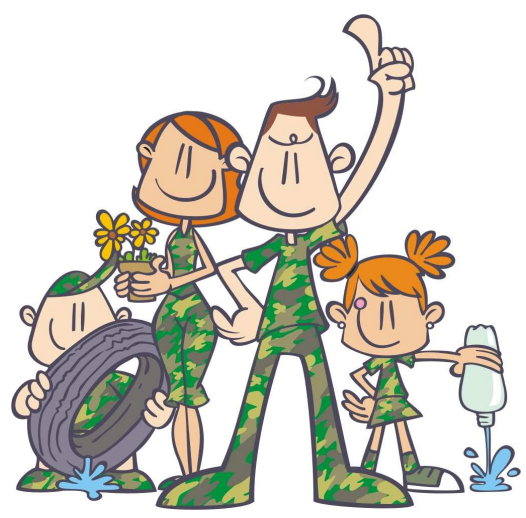

"Los pacientes infectados con el virus chikungunya son el reservorio de la enfermedad para otros en el hogar y en la comunidad"

\section{Alertas de Farmacovigilancia}

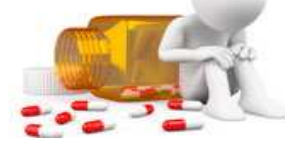

A continuación un breve resumen de las Alertas de Farmacovigilancia más relevantes publicadas por las agencias reguladoras internacionales durante los últimos meses.

\section{Bromocriptina}

La Agencia Europea del Medicamento (EMA) ha establecido mediante un consejo de expertos que se debe limitar el uso de bromocriptina para suspender la lactancia materna a dosis de $2,5 \mathrm{mg} /$ día en condiciones clínicas como pérdida del bebé durante o después del parto o en madres con infección VIH positivo.

Se recomienda que el medicamento no se prescriba de manera rutinaria debido a que la lactancia es un proceso que se suspende por si mismo al no suministrar leche al bebé. Por otra parte se sugiere que se vigile su prescripción en mujeres con factores de riesgo para desarrollar efectos adversos serios de tipo cardiovascular, neurológico o psiquiátrico principalmente.

http://www.ema.europa.eu/ema/ index.jsp?curl=pages/ news_and_events/news/2014/08/ news_detail_002157.jsp\&mid=WCOb0 1 ac058004d5c1, 21 de agosto 2014

\section{Docetaxel}

La FDA advierte que está solicitando cambios en los etiquetados del docetaxel y obligando a los fabricantes a declarar la presencia de etanol (alcohol) en las formulaciones.
El etanol puede hacer que algunos pacientes sientan síntomas de intoxicación alcohólica mientras están con ese tratamiento.

http://www.fda.gov/Drugs/ DrugSafety/ucm 402775.htm, 26 de junio 2014

\section{Dabigatrán}

La FDA mediante un estudio que compara Dabigatrán versus Warfarina en la prevención de accidente isquémico, hemorragia cerebral, hemorragia gastrointestinal severa, infarto de miocardio y muerte, llegó a la conclusión de que el 


\section{Continuación de las Alertas de Farmacovigilancia}

dabigatrán presenta mayores beneficios en la prevención de hemorragia cerebral y muerte, en comparación con warfarina.

El estudio también encontró un mayor riesgo de hemorragia gastrointestinal severa con el uso de dabigatrán en comparación con warfarina. El riesgo de infarto de miocardio fue similar con los dos medicamentos.

Lo más importante es que el nuevo estudio se basa en un grupo más numeroso y de mayor edad que el usado en el estudio previo de la FDA de datos posteriores a la comercialización, y utilizó un método analítico más sofisticado para captar y analizar los sucesos de interés.

http://www.fda.gov/Drugs/DrugSafety/ ucm397607.htm, 13 mayo 2014

\section{Interferores Beta (Avonex, Betaferon, Rebif)}

La Agencia Española del Medicamento y Productos Sanitarios (AEMPS) Informa que el uso de interferón beta se puede asociar a la aparición de microangiopatía trombótica y síndrome nefrótico, pudiéndose presentar desde varias semanas hasta incluso años después de iniciarse el tratamiento.

Se recomienda a los profesionales en salud vigilar la aparición de signos y síntomas de microangiopatía trombótica y de síndrome nefrótico. En caso de presentarse, se recomienda iniciar el tratamiento correspondiente y suspender la administración de interferón beta.

http://www.aemps.gob.es/informa/ $\mathrm{n} o \mathrm{t}$ a s I n o r m a t i va s/ m edicamentos U so H u m a / seguridad/2014/NI-MUH_FV_12-2014interferones.htm, 1 setiembre 2014

\section{Denosumab}

La AEMPS emite alerta recordando que la osteonecrosis mandibular y la hipocalcemia son dos reacciones adversas conocidas para denosumab en sus distintas indicaciones. Se recomienda a los profesionales en salud adoptar las medidas preventivas necesarias para evitar la aparición de ostenocrosis mandibular y/o hipocalcemia como son: revisión y mantenimiento de la higiene bucal al inicio y durante el tratamiento, evitando durante el mismo procedimientos dentales invasivos en pacientes con factores de riesgo. No se debe iniciar el tratamiento con denosumab en pacientes con patologías odontológicas que requieran cirugía o que no se hayan recuperado aún de una cirugía maxilofacial previa. http://www.aemps.gob.es/informa/ notasInformativas/medicamentosUsoHumano/ seguridad/2014/NI-MUH_FV_13-2014Denosumab.htm

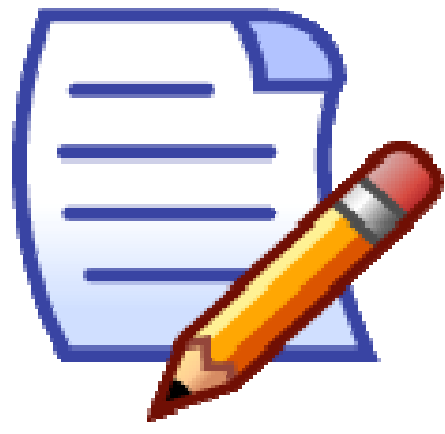

Redacción y diseño

Dra. Cristina Fernández Barrantes Farmacéutica

Hospital San Juan de Dios

Correspondencia: cristifdez@gmail.com farmacovigilanciahsjd@gmail.com

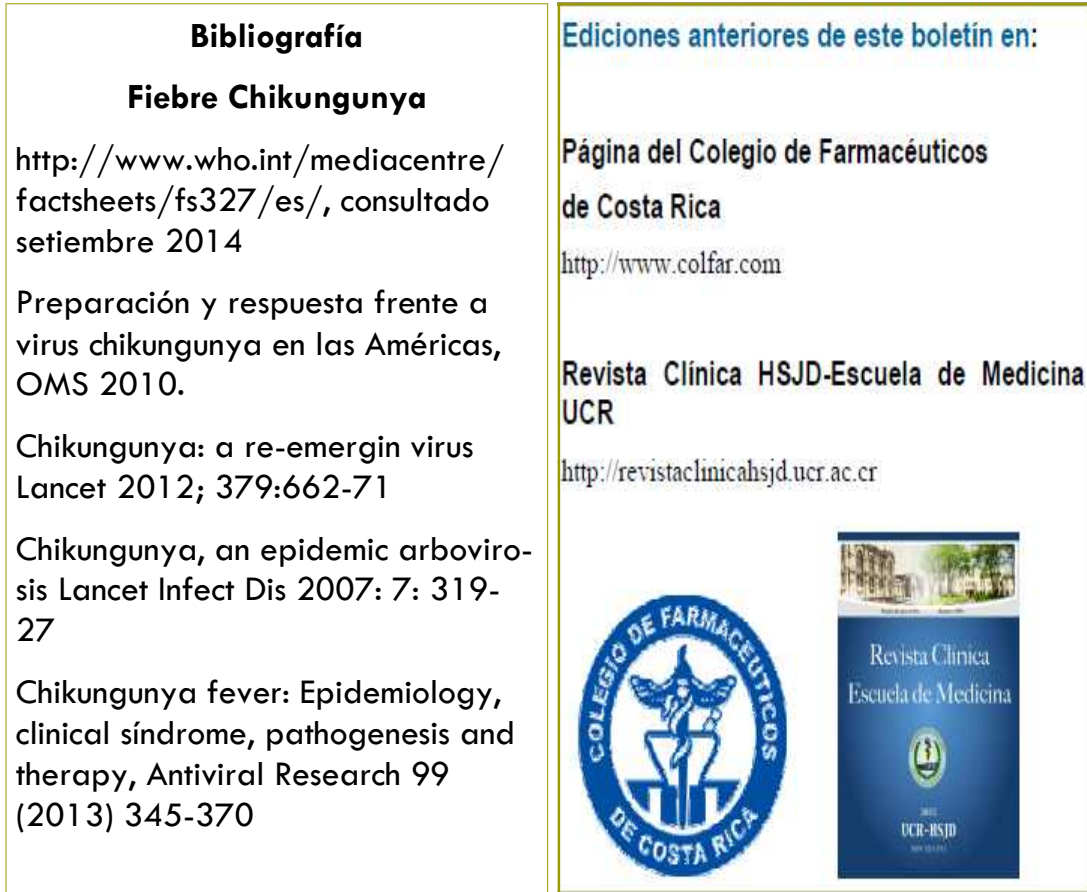

